\title{
ESTRATEGIAS, ARGUMENTOS, LÍMITES Y POTENCIALIDADES EN LA DEFENSA PENAL EN LA ARAUCANÍA MAPUCHE DE CHILE
}

\author{
STRATEGIES, ARGUMENTS, LIMITS AND POSSIBILITIES IN THE CRIMINAL \\ DEFENSE IN THE MAPUCHE ARAUCANÍA OF CHILE
}

\author{
Marcelo Berho ${ }^{1}$ Wladimir Martínez ${ }^{1}$
}

\begin{abstract}
En el presente artículo se analiza el desarrollo de un caso de defensa penal realizado en La Araucanía de Chile, en el que se condenó a un hombre mapuche por femicidio, el cual contó con la defensa especializada de la Defensoría Penal Mapuche el año 2013. A través del caso nos preguntamos en qué consistió la defensa realizada, de qué modo encaró la singularidad sociocultural, qué marcos de referencia teórico-metodológicos y recursos jurídicos incorporó en su argumentación y qué límites internos tuvo dicha práctica en el orden del convencimiento jurídico. El análisis considera las acciones de la defensa, la argumentación y la asimilación de categorías jurídicas exculpatorias y categorías de comprensión provenientes del universo cognitivo y médico mapuche. El valor de este caso radica en que, a través de él, es posible reconocer una forma de defensa penal sociocultural y visualizar los límites y potenciales pedagógicos que ésta tiene para una teoría y práctica penal pluralista y transformadora en contextos multiétnicos y multiculturales como el chileno actual.
\end{abstract}

Palabras claves: defensa penal, mapuche, estrategias, argumentación, homologación.

This article analyzes the development of a criminal defense case that took place in Chile's Araucanía Region in 2013, and in which a Mapuche man was convicted of femicide. The man's legal defense was provided by the specialized Mapuche Public Defender's office. In this article we examine the legal defense provided to this man, the manner in which the specific socio-cultural conditions were taken into account, the theoretical and methodological frameworks and juridical resources considered in the defense's arguments, and the internal limitations met by said arguments in terms of the judicial conviction. Our analysis covers the defense's actions, the arguments presented by the defense, and the assimilation of exculpatory legal categories and of categories of understanding that are typical of the Mapuche cognitive and medical worldview. This case is especially interesting because it allows us to recognize a specific type of socio-cultural legal defense and to derive lessons that can inform a pluralistic and fair legal theory and practice in multi-ethnic and multi-cultural contexts such as the Chilean society today.

Key words: Cultural criminal defense, Mapuche people, legal strategies, legal arguments, equivalence of categories.

Tras la reforma procesal penal del año 2001, el sistemade justiciapenal chileno comenzóa experimentar importantes cambios, al pasar de un modelo inquisitivo a otro acusatorio que otorga importancia central al juicio oral, inmediato y público en el proceso penal. El modelo establece la diferenciación de roles entre jueces, fiscales y defensores, la limitación de facultades discrecionales a fiscales, el reconocimiento de garantías al debido proceso, la presunción de inocencia y la afirmación de los derechos de las víctimas, a quienes entiende como actores relevantes del proceso (Duce 2014).

Este proceso se inició en las regiones de Coquimbo y La Araucanía, en el norte y centro sur de Chile, respectivamente. La Araucanía enfrentó la nueva institucionalidad con una realidad multiétnica históricamente asimétrica para la cual no estaba preparada y que ha conformado un espacio de conocimiento e interacción de poderes y saberes distintos y desiguales. La persistencia del pueblo mapuche en La Araucanía ${ }^{1}$ y los procesos políticos de reivindicación territorial que éste retomó en 1997 (Berho 2008), tuvieron consecuencias directas en la adecuación de la reforma procesal penal (Le Bonniec 2008). Entre estas adecuaciones se destaca la creación, en el año 2003, de una defensoría especializada a cargo de abordar de manera específica los casos penales que

\footnotetext{
${ }^{1}$ Centro de Estudios Socioculturales (CES), Departamento de Antropología, Universidad Católica de Temuco, Chile. mberho@uct.cl; hmartinez@educa.uct.cl
} 
implican a personas y/o grupos mapuche. La Defensoría Penal Mapuche (DPM), dependiente de la Defensoría Penal Pública de Chile (DPP), contó desde sus inicios con un defensor especializado y un facilitador intercultural, a cargo de promover el entendimiento comunicativo entre las partes. La figura del facilitador intercultural también se incorporaría al plantel del ente acusador, el Ministerio Público y las fiscalías. Otro de los aspectos emergentes concierne a la incorporación progresiva de peritos antropólogos en los casos en que las diferencias socioculturales y lingüísticas representan aspectos sustantivos en el proceso judicial, ya sea porque mediante ellos resulta un convencimiento o porque representan obstáculos procesales (Defensoría Penal Pública [DPP] 2012). Estos cambios son coherentes asimismo con los mandatos jurídicos nacionales e internacionales que el Estado chileno ha reconocido en cuanto al tratamiento de las diferencias socioculturales ${ }^{2}$.

En la práctica, estos ajustes institucionales han resultado en el desarrollo de juicios en los que la defensa esgrime argumentos de raíz sociocultural, cuya particularidad es desconocida por la mayor parte de los agentes (públicos y privados) de la justicia penal estatal. El presente artículo se enfoca en analizar uno de estos casos, relativo a lo que la criminalística estatal define como "femicidio", el cual contó con la defensa especializada de la DPM durante su desarrollo el año 2013. A través del caso nos preguntamos en qué consistió la defensa realizada, de qué modo elaboró la singularidad sociocultural, qué marcos de referencia y recursos incorporó en su argumentación y qué límites internos tuvo dicha práctica en el orden del convencimiento jurídico. Proponemos que el valor de este caso radica en que, mediante su análisis, es posible reconocer una forma de defensa penal sensible ante las diferencias socioculturales y visualizar los límites y potenciales pedagógicos que ésta tiene para una teoría y práctica penal pluralista y transformadora en sociedades multiétnicas y multiculturales.

Principalmente, el análisis se apoya en las experiencias de actuación de los autores como peritos antropólogos en casos de defensa penal de imputados mapuche de La Araucanía realizados para la DPM entre el año 2013 y 2017, así como en la revisión y análisis de contenidos de los documentos del caso ${ }^{4}$ y en las entrevistas realizadas a actores clave del proceso (abogado, facilitadores interculturales y perito antropólogo). El análisis explicita las prácticas, estrategias y teorías desplegadas por la defensora penal en el caso indicado, en el cual la argumentación sociocultural se impuso en la defensa por sobre cualquier otra argumentación (médica, socioeconómica y psiquiátrica).

Asimismo, realizamos una comparación entre el lugar que ocupa la diversidad cultural en ésta y en otras defensas históricas significativas que dan luces sobre la especificidad de la defensa realizada, sus alcances y límites. Para esto se revisaron las sentencias de dos casos en los cuales se aplicaron medidas eximentes de responsabilidad penal a personas mapuche. El primero de ellos, corresponde a un homicidio perpetrado por una joven mujer mapuche en contra de su abuela, una machi (agente médico y espiritual mapuche) - bruja, acaecido en 1953 en la zona andina de Trafun, en la región de Los Ríos 5 . El segundo caso, corresponde al conocido como "sacrificio humano", acaecido en el marco del maremoto de 1960, en Collileufu, en el Pacífico de La Araucanía ${ }^{6}$. Ambos casos son relevantes aquí pues, en ellos, al igual que en el caso de 2013, operó una defensa basada en una estrategia y argumentación orientada a homologar el marco cultural particular de los defendidos (mapuche) con el referido a la dogmática penal (estatal), cuyos límites y potencialidades se advierten al final.

\section{Actuación de la Defensa}

En julio de 2012, en un sector rural cercano a la ciudad de Temuco, capital de La Araucanía, un hombre de origen mapuche dio muerte a su mujer con la que llevaba más de treinta años de matrimonio. El hecho fue repudiado por la prensa y las organizaciones de derechos de la mujer en un contexto nacional en el que la violencia intrafamiliar y el femicidio constituyen ya una preocupación política y legislativa relevante ${ }^{7}$.

La defensa no discutió el crimen ni la muerte de la mujer sino que alegó la atribución de la autoría de su representado en los hechos y, por esta vía, relativizó la responsabilidad penal que al mismo le cabía. Se volcó, a establecer que, desde el punto de vista mapuche, su representado se encontraba afectado por una enfermedad culturalmente significativa. Al respecto, "solicita una apertura hacia el pluralismo jurídico, con distintas formas de ver el tema de la salud y la enfermedad". Y "pide apertura a una cosmovisión distinta" (Sentencia causa RIT 107-2013, p. 6) para comprender y valorar lo ocurrido.

En este sentido, la defensora subrayó que "se juzgue este hecho en su contexto y en su circunstancia específica, no como el décimo hecho a nivel nacional sino como este hombre, esta víctima, estos hechos que sucedieron" (Alegato de apertura de juicio, día 1, 08/08/13). Valiéndose de informes brindados por la facilitadora intercultural y un peritaje antropológico, incorporó antecedentes socioculturales del imputado. Adujo que éste era hablante de mapudungun (idioma de la tierra), practicaba la religión mapuche, participaba activamente en las distintas ceremonias de su pueblo y llevaba un estilo de vida conforme con las pautas culturales mapuche tradicionales y algunas derivadas del proceso de asimilación a la sociedad chilena. Resaltó, 
además, que su defendido era "ayudante de machi" y que tocaba la püfillka (instrumento de viento) en las ceremonias, de manera que tenía una clara inscripción en ámbitos significativos de la vida social mapuche.

Para contribuir a "juzgar el hecho en su contexto y circunstancia específica", la defensa relevó las voces de quienes podían decir algo significativo de la clase de situaciones a la que se enfrentaba el tribunal. Escuchó entonces lo que tenía que decir el representado y su familia. Sumó a estas opiniones las de un machi y un antropólogo. Además de éstos, la defensora recurrió a la asistencia lingüística-cultural a través de la participación de los facilitadores interculturales de su institución. De este modo, pudo configurar una teoría alternativa en la que afirmó la identidad mapuche del imputado y reconstruyó el contexto epidemiológico - cultural más amplio en el que ocurrieron los hechos, haciendo comprensible lo ocurrido en términos interculturales.

El enfoque jurídico adoptado en la defensa, se fundó en el Convenio 169 de la Organización Internacional del Trabajo (OIT), la Ley Indígena estatal, el modelo de defensa penal indígena de la DPP y, probablemente, en la etnicidad de la defensora a cargo (dada por su origen y pertenencia mapuche). La defensora se orientó a la absolución del imputado, invocando el artículo 54 de la Ley Indígena que hace valer la costumbre indígena, el artículo $10 \mathrm{~N}^{\circ} 1$, parte final ${ }^{8}$ y el artículo $10 \mathrm{~N}^{\circ} 9^{9}$ (ambos del Código Penal chileno) y su aplicación en el fallo de 1963 del caso de "sacrificio humano" en el que se absolvió a los involucrados.

Cabe señalar que las pruebas aportadas por el perito y los testigos de la parte acusadora y querellante -psiquiatra, familiares y amigo de la familia- ${ }^{10}$, fueron fuentes hábilmente aprovechadas por la defensa en el contrainterrogatorio y durante el desarrollo de la argumentación.

A través de estas actuaciones, la defensa penal "no pretend[ió] hacer creer que sea normal o natural darle muerte a una persona" ni tampoco "que sea eximente que un mapuche mate a otro sino que el concepto de enfermedad es distinto y puede subsumirse en la eximente" (Sentencia causa RIT 107-2013, p. 6). Este punto será central en la estrategia argumentativa de la defensa, a la vez que, como mostraremos, constituye un espacio problemático desde el punto de vista interpretativo. $\mathrm{Al}$ respecto, nos enfocaremos en los juegos teóricos y retóricos de la defensa respecto de las categorías socioculturales mapuche en relación con las categorías de la dogmática penal.

\section{Argumentación de la Defensa}

Los argumentos de la defensa reposan en la premisa de la no participación de su representado como autor directo en los hechos que se le imputan, bajo el entendido de que éste no recordaba nada de lo ocurrido. Según la defensora, su representado padecía una enfermedad mapuche, la cual le había provocado una alteración de conciencia temporal que lo afectó cuando cometió el crimen.

¿Cuál era la enfermedad mapuche a la que se refería la defensora? ¿De qué modo su comprensión de esta enfermedad se enlazó con una defensa situada que adujo razones socioculturales? De acuerdo con el imputado, él tenía "un mal" que le habían ocasionado terceros por sobrepasarse con una mujer en una cantina. Señalaba que el diablo se había apoderado de él y que padecía "mal del piwke (corazón)" y "enfermedad de la cabeza". Para los cercanos al defendido, éste "presentaba una conducta extraña, como angustiado, lloraba todo el tiempo diciendo que no sabía qué le pasaba, no quería ver a nadie y estaba cansado de los malos tratos que le daban su señora y sus hijas" (Alegato de apertura defensa, día 1, 08/08/13). En cierta ocasión, la esposa del imputado le contó a su hermana que éste seguía un tratamiento con machi porque tenía visiones que lo atormentaban. Una de las hijas y una prima del imputado, así como un amigo cercano a la familia, coincidieron durante el juicio en afirmar que al jefe de hogar le habían provocado un "mal". Existía entre ellos una noción común respecto de la situación de salud que aquejaba al imputado, la cual remite a una clasificación y terapia distinta a la del paradigma biomédico, pero no por ello totalmente ajena a los marcos de comprensión de los jueces.

Según la defensa, en tanto, la enfermedad que padecía el imputado era parte de lo que los machi ${ }^{11}$ denominan mapuche kutran, un tipo de enfermedad que solo afecta a los mapuche. En base a las evidencias aportadas por el machi y el antropólogo, la defensa estableció que el imputado padecía una enfermedad propiamente mapuche de la cual venía siendo tratado desde antes del homicidio. Según nuestro análisis, el imputado recibió atención de parte de tres machi (dos hombres y una mujer), dos de los cuales lo asistieron antes del crimen y un tercero tras su realización. Entre los machi hubo ligeras diferencias en cuanto al diagnóstico, mientras que la machi ofreció una opinión distinta. Así, los dos primeros, coincidieron en diagnosticar la existencia de mapuche kutran, mientras que la tercera machi atribuyó el desequilibrio a la acción de terceros denominados $k a l k u^{12}$, otorgando así el sustento a los dichos del imputado y sus familiares respecto del diagnóstico.

En la concepción mapuche, la palabra kutran remite a una noción más amplia del dolor o de la enfermedad misma, la cual engloba a la comunidad, la familia, la persona y el conjunto de las fuerzas vivientes, visibles e invisibles (Caniullán 2000; Centro de Estudios Socioculturales [CES] 2003). Bajo el entendido de que 
los seres humanos son parte de una trama relacional que los liga al cosmos, kutran es un estado de desequilibrio desatado por la transgresión y/o el descuido de la tradición en distintos órdenes del mundo humano y no humano natural y espiritual. Para enfrentar los distintos kutran, el sistema de salud mapuche se organiza en términos de agentes, recursos y prácticas terapéuticas de distinta complejidad, que abarcan desde la medicina herbolaria sustentada en el conocimiento familiar de transmisión oral, hasta la medicina chamánica asociada a una configuración socio-espiritual y territorial más amplia en la que intervienen diversas agencias.

El machi que actuó como testigo en el tribunal -con quien el imputado se atendió tras los hechosdio a conocer las concepciones mapuche de salud y enfermedad y expuso una taxonomía en la que distinguió seis clases de kutran $^{13}$. Adujo que cuando atendió al imputado éste presentaba re kutran ${ }^{14}$ y mapu kutran ${ }^{15}$. Sobre esta última clase de kutran precisó que "tiene que ver con energías o fuerzas que están en la tierra y provocan algún tipo de alteración en la persona" (Sentencia causa RIT 107-2013, p. 34). Dichas fuerzas se desatan cuando la persona incumple los mandatos culturales y religiosos de relación cosmológica y vital. Según el machi, al transgredir el orden natural y espiritual establecido, "son fuerzas, son energías, o son espíritus que se acercan al cuerpo de la persona, y [ésta] comienza a sentir algún tipo de malestares" (Declaración testigo machi, día 2, 09/08/13). Interrogado por la defensa acerca de su diagnóstico, el machi relató que el hombre presentaba problemas de sueño, pesadillas, visiones y sensaciones de ser perseguido o asediado por presencias que afectaban su estabilidad psicológica, social y espiritual. Afirmó que estos síntomas los observó desde la primera vez que examinó la orina del enfermo.

De acuerdo con su diagnóstico, el machi descartó completamente la presencia de weza kutran o "mal". En respuesta a uno de los acusadores que interrogó al machi al respecto, éste aseveró que "weza kutran son enfermedades [en que] personas especializadas preparan algún efecto, por así decirlo, venenoso para darle a la persona, y ese tipo de enfermedad daña directamente al organismo, directamente se va al intestino y al tema biliar, y en este caso no era la situación" (Declaración testigo machi, día 2, 09/08/13). En cambio, adujo, el caso "tiene que ver con energía, o fuerza que está en la tierra, que provoca algún tipo de alteración en la persona y, en el caso específico de la persona que me fue a consultar, tenía muchas dificultades para dormir, tenía ciertas sensaciones de perseguimiento, pesadillas y, en el fondo, esas eran situaciones que también le provocaba inestabilidad dentro de su entorno" (Declaración testigo machi, día 2, 09/08/13). Sostuvo que dichas alteraciones "dependen mucho del comportamiento de las personas con su entorno, con la tierra, con las aguas, etc. Muchas veces el espíritu comienza a debilitar el espíritu de la persona y en este caso es lo que estaba sucediendo" (Declaración testigo machi, día 2, 09/08/13). Finalmente, se refirió al tratamiento indicado por él, sobre el cual no pudo asegurar si había sido seguido o no por el enfermo.

Esta perspectiva de la enfermedad del imputado fue corroborada por el antropólogo que perició el caso a petición de la defensa. En su informe escrito y en su declaración en el juicio, el especialista aportó elementos descriptivos sobre algunos rasgos del modelo médico mapuche, relativos a la nosología, la etiología y la terapéutica de las enfermedades. Argumentó que en "la cosmovisión mapuche el orden del universo se rige por una serie de fuerzas opuestas y complementarias que deben estar en armonía. El desequilibrio se produce por la intervención humana o de la naturaleza, que entra en conflicto y que requiere la recomposición del sistema. Se origina entonces lo que los mapuche llaman kutran o enfermedad, estado anormal en que el individuo no puede relacionarse como habitualmente lo hace" (Peritaje antropológico causa RIT 107-2013, p. 13).

En el juicio el perito afirmó que no hubo acción de terceros humanos contra el imputado sino más bien de "fuerzas o newen de la tierra", uno de los cuales "lo habría tomado y esa enfermedad le habría provocado un desequilibrio sistémico" (Sentencia causa RIT 1072013, p. 38) que alteraba totalmente su salud. Al igual que el machi, adujo que el imputado sufría mapu kutran, "porque las personas no siguen las normas tradicionales que están pautadas culturalmente y que son territoriales" (Sentencia causa RIT 107-2013, p. 38). Al incumplir o infringir las normas, tanto el imputado como su familia, su casa y hasta su comunidad "habría tenido una suerte de afectación" y que para revertir esta situación el imputado, su familia y comunidad "tenían que realizar ciertas ceremonias y en eso habían fallado" (Sentencia causa RIT 107-2013, p. 39).

Otra de las evidencias que recogió la defensa para argumentar a favor de la enfermedad mapuche de su representado, concierne a mostrar la existencia de prácticas y conocimientos compartidos del diagnóstico y la terapia en el círculo de cercanos de aquél. Antes del hecho, la víctima había buscado ayuda para su esposo con un machi cercano a su familia. Empleando las pruebas de los acusadores, la defensa mostró que los hijos del matrimonio y otros familiares sabían que su representado estaba enfermo y que seguía un tratamiento médico con machi. Mostró que el imputado tomaba lawen (remedio mapuche) antes y después de quitarle la vida a su esposa. Advirtió que el tratamiento no fue sostenido y que tanto el agresor como su familia no favorecieron la continuidad terapéutica y, con ello, la sanación. 
Frente a la teoría de los acusadores, según la cual el imputado actuó bajo una crisis alcohólica, la defensa se mostró imperturbable y desafiante. Para el psiquiatra del Servicio Médico Legal que evaluó al defendido por encargo del Ministerio Público, éste no presentaba ninguna psicopatología que pudiera explicar, desde el punto de vista médico, el móvil de sus actos. Antes bien, en las dos oportunidades que realizó la evaluación, el psiquiatra sospechó acerca de la veracidad del "mal" que afirmaba tener el imputado, llegando a pensar que se trataba de una treta de éste para justificar su delito y excluirse de responsabilidad. Para la defensa, el psiquiatra descuidó totalmente el contexto sociocultural de vida de su representado y fue incapaz de indagar adecuadamente en el significado del "mal" y el tratamiento de machi.

En el contrainterrogatorio, la defensa conduce al perito psiquiatra a decir que él y su equipo "no logran descartar ni afirmar que exista una enfermedad propiamente mapuche" (Declaración perito psiquiatra, día 2, 09/08/13). En cambio, el argumento de la defensa afirma que, en virtud de los dichos del machi que concurrió al juicio como testigo, "solo el sistema de salud mapuche puede entender lo que es mapu kutran por una visión religiosa que tienen del entorno, del ambiente" (Sentencia causa RIT 107-2013, p. 35). De este modo, descartó la perspectiva psiquiátrica debido a la clausura epistemológica para abordar un cuadro ignorado en la nosología biomédica dominante.

En contraposición a la visión psiquiátrica, la defensa mantuvo la teoría de la enfermedad mapuche como fundamento argumental para solicitar la absolución de su representado. Para la defensora, la enfermedad mapuche de su defendido era más o menos equivalente con la clase de estados que admite la dogmática jurídica respecto de los eximentes de responsabilidad penal. Particularmente, trazó una equivalencia entre el planteamiento exculpatorio del artículo $10 \mathrm{~N}^{\circ} 1$ en su parte final, con los síntomas de su defendido, observados por sus familiares y los machi que lo atendieron. La amnesia, las conductas extrañas y el "andar como loco" fueron todos indicios que, a juicio de la defensora, podían circunscribirse en el ámbito de las eximentes de imputabilidad penal.

\section{Asimilación de Categorías Jurídicas Estatales y Categorías Médicas Mapuche}

La defensa argumentó la absolución del imputado a partir de la homologación de elementos de la cultura médica mapuche y las categorías jurídicas exculpatorias propias del derecho penal positivo. Pero, ¿en qué sentido ambos marcos de significación son realmente homólogos? La homologación es una especie de equivalencia intercultural que busca poner en igualdad de condiciones dos racionalidades distintas, basadas en experiencias y conocimientos no necesariamente irreductibles, pero comparables. El punto de encuentro entre las categorías jurídicas penales estatales y las categorías médicas mapuche sería la enfermedad que afectaba la conciencia y voluntad del imputado, la cual, de ser aceptada por el juzgador, lo situaría como una persona inimputable y, por tanto, susceptible de ser absuelta.

La asimilación de categorías penales estatales y mapuche estuvo presente en el tratamiento de los casos históricos, en los cuales se absolvió a los imputados mapuche. En ambos casos, la figura exculpatoria fue la de la "fuerza psíquica irresistible o miedo insuperable" del código punitivo (artículo $10 \mathrm{~N}^{\circ}$ 9) (Villegas 2012). En el caso del sacrificio humano en la costa del Pacífico en 1960, la categoría jurídica se aplicó al sacrificio del menor en tanto acción desesperada y última en una cadena de acciones previas ${ }^{16}$, orientada a aplacar las fuerzas espirituales encolerizadas por el abandono progresivo de los mandatos cosmológicos por parte de los mapuche (Leiva 2013). Por su parte, el asesinato de la machi-bruja a manos de su nieta, acaecido en 1953 en una aislada zona de Panguipulli, fue conceptualizado como la realización del irreprimible impulso de restablecer el equilibrio alterado por la acción brujeril de la anciana, la cual no solo afligía a la joven madre sino al conjunto de la comunidad.

Según se infiere de las declaraciones del machi y el perito antropólogo que concurrieron por la defensa en el caso contemporáneo, mapu kutran fue el resultado de las transgresiones infringidas por el propio imputado al orden cosmológico mapuche, en lugar que por la agencia de terceros -como ocurrió en el asesinato de la machi-bruja en Trafun-, o producto del abandono de la tradición -como se dio en la costa del Pacífico en el caso del sacrificio humano-. En el primer caso la jueza llegó al convencimiento de que la joven homicida actuó motivada por una "fuerza irresistible", "pues estaba convencida que su abuela era bruja". Dadas las circunstancias específicas de vida de la joven madre expuestas por los "peritos indigenistas", consistentes en "una comunidad primitiva dominada por tradiciones y supersticiones arcaicas, [donde] la hechicería es, dentro de esas creencias, un peligro real", "no se le podía pedir o exigir otra conducta" (Mardones 1955:99). En el caso del sacrificio humano, el juez adquirió el convencimiento de que los imputados "fueron incapaces de actuar en forma racional ante el peligro inminente de perder sus vidas amagados por fuerzas naturales que creyeron poder calmar" (Causa rol no $24.228,2$ de octubre de 1962). Este argumento se sostuvo bajo la premisa de que los imputados eran "un sector de la población indígena que dio claras demostraciones de estar en una etapa de civilización que hace imposible 
responsabilizarlos por la acción cometida" (Causa rol $\mathrm{n}^{\circ}$ 24.228, 2 de octubre de 1962). Al igual que en el de Trafun, en el caso del Budi, el convencimiento del juzgador estuvo dado por la comprobación objetiva de la existencia de costumbres imperativas sobre las conductas individuales.

En ambos casos históricos, los jueces concluyeron que los imputados hicieron lo que debían hacer en virtud de sus marcos normativos de orden religioso y moral. Se exculpó entonces a los mapuche por su atavismo, el que los mantenía sometidos a ideas irracionales propias de los pueblos primitivos. Nos preguntamos entonces si este tipo de razonamiento era o no aplicable, como lo pensó en su momento la defensora, al caso contemporáneo.

Como se consignó más arriba, la defensora insistió en que "jamás planteó la existencia de un mal o de brujería ni que el imputado haya realizado estos hechos bajo una eximente de responsabilidad; lo que planteó es que tiene una enfermedad mapuche y que en ese período [él] estaba privado temporalmente de razón" (Sentencia causa RIT 107-2013, p.6). Esta visión fue obviada tanto por la parte acusadora como por los jueces, quienes finalmente condenaron al agresor basándose en el supuesto erróneo de que la defensa no logró demostrar fehacientemente la existencia de brujería, en circunstancias de que dicha proposición no fue realmente expuesta ni argumentada por ella.

\section{Resultados y Balance Crítico de la Estrategia de la Defensa}

A diferencia de los casos históricos, en el caso contemporáneo la defensa no logró la absolución. No obstante, al igual que en esos casos, colocó un tema complejo, referido a las concepciones y prácticas de salud - enfermedad entre los mapuche, en el escenario jurídico. Los tres casos impusieron, de este modo, la necesidad de abrirse a entender circunstancias, acciones y nociones incomprensibles desde el punto de vista de la lógica y la causalidad de las ciencias positivas. Curiosamente, al increpar a la defensa no haber fundado debidamente la tesis del "mal" atribuido a la brujería, los jueces aparecen admitiendo la existencia de ésta, pero no de las enfermedades mapuche, aun cuando el "mal" es un tipo de éstas en la perspectiva mapuche habitual y castellanizada.

La defensa se construyó a la luz de los "componentes culturales" y específicamente del universo cognitivo y médico del imputado para efectos de excluir la responsabilidad penal de éste, con lo cual ella puede adscribirse a la llamada defensa cultural (Carnevali 2007; de Maglie 2012). Para desarrollar este tipo de defensa "es preciso que se esté frente a delitos cuya motivación obedezca a razones culturales"
(Carnevali 2007:25), o que la acción esté anclada a la "buena fe, basada en la herencia o tradición cultural" (de Maglie 2012:137). A su vez, la acción del autor de un delito culturalmente motivado descansa, ya sea en el desconocimiento total o parcial del orden penal dominante ${ }^{17}$, o bien en la naturaleza imperativa de su cultura originaria, la cual es superior a cualquier ordenamiento jurídico externo a dicha cultura ${ }^{18}$.

La argumentación de la defensa introdujo un marco de inteligibilidad sobre asuntos culturalmente incomprensibles desde el puntode vistade laracionalidad imperante en el campo jurídico y de sentido común de la cultura chilena. A diferencia del tratamiento brindado en los casos históricos, basados en el uso de un marco teórico evolucionista que ubicaba a los mapuche en un estadio arcaico del desarrollo cultural -a quienes asigna una "mentalidad prelógica" y ve incluso como gente sin cultura-, la defensa contemporánea buscó establecer la legitimidad de las concepciones epidemiológicas mapuche.

Si bien en los dos casos históricos analizados se contó con la participación de "peritos indigenistas"19, solo en el caso reciente la identidad del imputado fue problematizada. Asimismo, en todos los casos los testigos son principalmente parientes y vecinos mapuche de los imputados, mientras que solo en el caso reciente, un machi -es decir, una autoridad médico religiosa- participa en el juicio. En el caso de Trafun (sobre el cual existe evidencia) el análisis pericial se enfocó en el estudio de fuentes secundarias, históricas y etnológicas, mientras que en el caso contemporáneo se incluye la perspectiva de los actores y sus marcos de referencia particulares ${ }^{20}$

La incorporación de un machi en el juicio avanzó en dos sentidos: por un lado, marcó un límite epistemológico entre el diagnóstico y la nosología biomédica psiquiátrica y la mapuche al interior de la defensa. Por otro lado, relevó -al menos para la defensala autoridad epistemológica de dicho agente respecto de materias desconocidas en tribunales y en general en la sociedad chilena. Este hecho es coherente con los principios del pluralismo jurídico subyacente al Convenio 169 de la OIT invocado por la defensa, así como con las teorías descolonizadoras en el campo jurídico que afirman las competencias jurídicas y normativas de las agencias indígenas (Sousa Santos y Exeni 2012). En este sentido, la defensa estuvo a tono con las exigencias jurídicas e institucionales globales que se auto-imponen los Estados al reconocer los derechos indígenas. El reto lanzado por la defensa, orientado a una mayor apertura a la diversidad sociocultural, es propio de las democracias que, según de Maglie (2012:136) "se están transformando en sociedades multiétnicas y que están llamadas a declarar sobre su tolerancia hacia la diversidad cultural". 
Respecto de la teoría de la defensa, ésta se fundó principalmente en la exposición e ilustración de las categorías cognitivas de la enfermedad entre los mapuche, las que fueron refrendadas por el machi y el perito antropólogo. Sin embargo, dicha exposición fue somera y no logró brindar un cuadro cabal de la nosología, etiología, sintomatología y terapia del caso concreto, que sostuviera de manera sustantiva y contundente la teoría del caso. Solo el machi dio luces acerca del cuadro específico que padecía el imputado, el cual fue designado como inakon ${ }^{21}$, al ser interrogado por uno de los jueces ${ }^{22}$. Este hecho fue visto como un vacío probatorio por parte de los juzgadores, para quienes la evidencia aportada por la defensa -a favor de la teoría según la cual el crimen se produjo bajo un estado de desequilibrio propio de mapu kutran- no fue suficiente. ¿Por qué el imputado cogió inakon? ¿Qué normas de conducta mapuche infringió efectivamente el imputado? ¿Por qué éste hablaba de un "mal" y no de mapu kutran? Son todas preguntas que por entonces y hasta el presente precisan ser formuladas y contestadas.

Para homologar categorías disímiles de pensamiento, provenientes de la dogmática penal y la medicina mapuche, la defensa requería contar con una base de argumentación sociocultural más sólida que la esgrimida en el juicio. Para efectos persuasivos, pudo brindarle al juzgador un cuadro específico acerca de la sintomatología de la enfermedad mapuche atribuida al imputado, con el cual mostrar similitudes verosímiles con las concepciones de demencia incrustadas en la psiquiatría y el penalismo occidental -el cual resuena en el artículo $10 \mathrm{~N}^{\circ} 1$ del código punitivo chileno-. Tanto la visión del machi, como la del antropólogo, pudieron profundizar al respecto, contribuyendo así a una comprensión intercultural.

Una teoría del caso enraizada en las particularidades epidemiológicas del marco cultural del defendido, solo puede ser valorada adecuadamente atendiendo al universo simbólico de referencia en el que se inscriben las experiencias y significados de la enfermedad de aquel. Así, para evitar caer en la trampa colonial de la homologación de categorías de comprensión provenientes de marcos socioculturales disímiles, es necesario y posible propiciar el legítimo derecho al ejercicio del derecho propio. Pero, como arguyó uno de los abogados defensores que apoyó a la defensa en su momento, esta última práctica era insostenible en su momento. De manera que, para él, la homologación fue "la única" estrategia jurídica a la cual pudieron recurrir entonces, atendiendo principalmente al contexto judicial monista y a la presión social y mediática condenatoria que envolvió los hechos, comprendidos únicamente bajo el rótulo de femicidio.

En lo social, faltó una distinción clara de las perspectivas mapuche respecto de las concepciones de salud - enfermedad mapuche y las categorías empleadas en su designación según las posiciones de los actores. La defensa hubiese podido evitar -o al menos contestarel desenlace condenatorio si hubiese distinguido entre los puntos de vista esotéricos y exotéricos (Turner 2008), empleados respectivamente por los especialistas y los legos mapuche para referirse al ámbito específico de las experiencias de enfermedad mapuche. En este caso, convenía discernir la comprensión del machi versus la de los familiares y conocidos acerca de la clase de desequilibrio experimentado por el imputado. Esta distinción debió ser informada oportunamente, ya sea por la defensora o por los expertos que participaron en el caso. Su omisión por estos actores resultó en la reproducción de una visión de sentido común entre los mapuche no expertos, y condujo a la afirmación etnocéntrica por parte de los jueces sentenciadores, según la cual el imputado habría actuado movido por un "mal" provocado por terceros.

De haber tratado oportunamente lo anterior, la defensa habría provisto para sí y los juzgadores una traducción más fina y adecuada de la clase de argumentos que precisan las partes para entender una situación de alteridad en un contexto monocultural. Así, se hubiese realizado una defensa cultural fuerte.

A diferencia de los casos históricos expuestos, el caso contemporáneo no fue suficientemente definido por la defensa en cuanto a la motivación sociocultural que condujo al femicidio, de acuerdo con la criminalística chilena. Así, en el sacrificio humano se tuvo en cuenta el convencimiento según el cual, "para calmar el mar, había que lanzar a un niñito". Según consta en el expediente del caso, "los ancianos decían que era una costumbre de sus antepasados hacer sacrificios humanos para evitar grandes calamidades" (Causa rol n ${ }^{\circ}$ 24.228, 2 de octubre de 1962). En el otro caso, la joven homicida "sabía que matándola [a su abuela machibruja] y chupándole la sangre se iba a mejorar, pues esas son las creencias de su raza" (Mardones 1955:86). La situación de vida o muerte que experimentó la agresora ante la amenaza brujeril se resolvió, en último término, a partir de la decisión de destruir esa amenaza en pro de la conservación y la salud personal y colectiva ${ }^{23}$. Asimismo, en este caso y en el del sacrificio, se estima que los involucrados desconocen el ordenamiento jurídico estatal, pues se encontrarían viviendo en un estadio de evolución cultural primitivo que los torna inimputables ${ }^{24}$.

Antes que en una motivación sociocultural, la especificidad del caso contemporáneo se fundamentó en el conocimiento de un contexto de relaciones y significados marcados por la singularidad a partir de la cual se organiza la experiencia y el sistema de salud-enfermedad entre los mapuche. El enfoque de la defensa cultural exige establecer claramente la fuente 
de la motivación cultural que podría haber informado la decisión del autor (de Maglie 2012), lo cual tiene claras implicaciones metodológicas en la teoría de la defensa. Por un lado, no era posible que ésta sostuviera la fuente cognitiva de la motivación, según la cual "el bagaje cultural del autor le impide entender que su comportamiento integra un delito" o contradice las leyes dominantes. Por otro lado, tampoco podía apelar a que el autor, conociendo el orden penal dominante, hubiese actuado "movido por la fuerza imperativa de su cultura de origen" (de Maglie 2012:137). Si, como señala Bacigalupo (2001), las "enfermedades espirituales" mapuche pueden presentar entre sus síntomas episodios de agresividad y amnesia, tanto la volición como la cognición de la persona que las padece se verían alteradas ${ }^{25}$. De este modo, la tarea de trazar el correlato entre la inimputabilidad y la acción concreta del imputado representó una meta muy compleja de alcanzar por parte de la defensa.

\section{Conclusiones}

La defensa desplegada en el caso analizado estuvo anclada a una estrategia y argumentación cultural que consideró, en primer lugar, la identificación del ofensor como miembro de la sociedad mapuche, $y$, en segundo lugar, la búsqueda de antecedentes contextuales que le permitieran situar adecuadamente las circunstancias epidemiológicas bajo las que ocurrieron los hechos. Para esto la defensa hizo concurrir al juicio a un representante autorizado del universo cultural y médico mapuche invocado, quien, junto con familiares de la víctima, confirmaron el padecimiento del agresor.

La defensa aceptó el hecho criminoso, no lo negó, pero tomó distancia respecto de su causalidad. El defendido no incurrió en un crimen por las razones esgrimidas por el Ministerio Público y los querellantes: algo así como "odio" a la víctima por ser mujer. A juicio de la defensa -y, como sucedió en el caso del sacrificio humano de 1960 y en el asesinato de la machi-bruja de 1953-, su representado actuó "bajo una eximente de responsabilidad contemplada en el código penal" (Sentencia causa RIT 107-2013, p. 4).

En cuanto a los marcos de referencia teóricometodológicos utilizados por parte de la defensa en su argumentación, hubo cierto reconocimiento a lo que sería un principio de pluralismo jurídico, basado en la aceptación de la diversidad cultural. Esto se expresó en la afirmación de la alteridad epidemiológica que debía enfrentar el tribunal y también del carácter experto del machi que actuó en el juicio. El recurso argumental más importante empleado por la defensa consistió en lo que denominamos homologación de un marco cultural de comprensión de la realidad dentro de otro marco. En particular, tal homologación operó como la asimilación de las categorías de comprensión mapuche en el seno de las categorías de comprensión jurídicas del Estado chileno. El resultado del cruce entre la apelación al pluralismo jurídico con la adopción de procesos de homologación, lleva a una suerte de defensa en la que, si bien se introduce la alteridad, ésta se desvanece bajo la primacía de la ideología de la igualdad. La comparación de casos penales con imputados mapuche, permitió visualizar el uso de la homologación como un mecanismo de comprensión y persuasión jurídica adoptado en un sistema inquisitorial (pre-reforma procesal penal) y acusatorial (hijo de la reforma), en los cuales las diferencias socioculturales son reconocidas parcialmente.

Respecto de los límites de la defensa desplegada, vemos en primer término que la homologación representó un ejercicio de comprensión intercultural de baja intensidad, pues en él, las claves de significación y poder ya han sido definidas con anticipación a partir de uno de los marcos de referencia, en este caso del jurídico estatal. Más que conformar una instancia de comprensión mutua, la homologación es una instancia acomodaticia de un orden de significación y poder en otro que goza de total o plena legitimidad y autoridad. Así, como recurso argumental, la homologación tiene una doble faceta. Por un lado, representa un ejercicio parcial y unilateral de comunicación intercultural y eventual diálogo inter-legal, y por otro lado, opera como un modo de obliteración de la alteridad y, por lo tanto, como una práctica que reproduce las asimetrías de relación y posición entre los Estados y los pueblos indígenas ${ }^{26}$.

La defensa actuó apropiadamente al buscar establecer una explicación cultural, en lugar que determinar la motivación cultural subyacente a la acción típica. De haberse orientado hacia el establecimiento de la motivación cultural, la defensa tendría que haber trazado la correspondencia entre la causalidad psicológica de la acción y los principios o valores culturales. Como hemos planteado, solo en casos límite, como el del maremoto de 1960 o el de la machi-bruja de 1953, se acepta el asesinato como una acción razonable. Bajo estados de no-conciencia, tal motivación es prácticamente imposible de sostener. De allí que la explicación cultural haya constituido un camino plausible que permitió una valoración general del comportamiento, las actitudes y circunstancias específicas bajo las que actuó el imputado.

Cabe señalar que, de acuerdo con los teóricos de los "delitos culturalmente motivados", la defensa de imputados con culturas "minoritarias" o, como en este caso, provenientes de un pueblo originario, solo aplican a delitos en los que no ha habido violación de los derechos humanos fundamentales. De allí, entonces, que pueda entenderse la decisión condenatoria asumida 
por el tribunal contra el imputado, decisión que recuerda que hay derechos humanos que prevalecen sobre los derechos indígenas. En todo caso, a tal decisión subyace también un límite epistemológico, el cual concierne a que conocemos solo lo que nuestros marcos de referencia nos permiten conocer. En el caso analizado, la deliberación final acreditó el conocimiento psiquiátrico en lugar que el propiamente médico mapuche, al cual desautorizó cuando aceptó de manera acrítica la visión exotérica (Turner 2008) del "mal” brujeril.

Todo lo anterior es representativo del modelo de defensa penal cultural que de Maglie (2012) denomina débil. Es decir, una defensa que, en este caso, da lugar a la expresión de las concepciones mapuche de enfermedad, como parte de la explicación cultural del ilícito, encuadrándolas en el marco jurídico penal dominante.

Agradecimientos: Los autores agradecen a los colegas Fabien Le Bonniec y Pamela Nahuelcheo de la Universidad Católica de Temuco, por facilitarnos los registros de audio del juicio oral del caso. A los abogados de la DPP de Temuco, Mario Quezada y Marcelo Pizarro, por el interés mostrado hacia la investigación antropológica y los potenciales usos de ésta en la defensa penal especializada. Al peñ $i$ (hermano) Horacio Cheuquelaf, facilitador intercultural de la DPM de Temuco, por su colaboración y tiempo para aclararnos dudas sobre el proceso de defensa indígena y mostrarnos la vigencia del derecho mapuche y la necesidad de trabajar por garantizar su ejercicio efectivo. Al kimeltuchefe (profesor) Gabriel Llanquinao, académico de la UC Temuco y colaborador del CES, por sus iluminadoras conversaciones sobre el universo cognitivo y lingüístico mapuche. A Yazmín Velásquez, de la carrera de Arqueología de la UC Temuco, por el apoyo brindado en la transcripción del registro de audio y por su participación entusiasta en el análisis colectivo de dicho material. Por último, agradecemos a los evaluadores externos del presente artículo por sus atinados comentarios críticos, los cuales permitieron tratar de manera más precisa algunos aspectos jurídicos expuestos.

\section{Referencias Citadas}

Bacigalupo, AM. 2001. La Voz del Kultrun en la Modernidad. Ediciones Universidad Católica de Chile, Santiago.

Berho, M. 2008. Cultura y política en la insurgencia mapuche contemporánea, La Araucanía, 1992-2007. Prácticas de Oficio. Investigaciones y Reflexiones en Ciencias Sociales 3:1-24.

Caniguan, N. 2013. Relatos del Sacrificio en el Budi. Ediciones LOM, Santiago.

Caniullan, V. 2000. El mundo mapuche y su medicina. En Acercamientos Metodológicos Hacia Pueblos Indígenas. Una Experiencia Reflexionada Desde La Araucanía, Chile, editado por T. Durán, E. Parada y N. Carrasco, pp. 123-140. Ediciones LOM, Centro de Estudios Socioculturales, UC Temuco, Temuco.

Caniullan, V. y F. Mellico 2017. Mapuche lawentuwün. Formas de medicina mapuche. En Mapun Kimün. Relaciones Mapunche Entre Persona, Tiempo y Espacio, editado por R. Becerra y G. Llanquinao, pp. 41-61. Ocho Libros, Santiago.

Carnevali, R. 2007. El multiculturalismo: un desafío para el derecho penal moderno. Política Criminal 3 (A6):1-28.

Centro de Estudios Socioculturales 2003. Mapunche Kümelkalen ka ixofij mogen: kimün egu rakizuam. Estado contemporáneo de la medicina mapunche en tres zonas del territorio mapunche. Un estudio en salud mapuche y medio ambiente. http//:www.memoriachilena. cl/602/articles-122901_recurso_7.pdf (19 mayo 2018).

Citarella, L. (compil.) 1995. Medicinas y Culturas en La Araucanía. Editorial Sudamericana, Santiago.

Defensoría Penal Pública 2012. Modelo de Defensa Penal Indígena. Centro de documentación Defensoría Penal Pública, Santiago.

De Maglie, C. 2012. Los Delitos Culturalmente Motivados. Ideologías y Modelos Penales. Marcial Pons, Ediciones Jurídicas y Sociales, Madrid.

Duce, M. 2014. La Prueba Pericial en los Sistemas Procesales Penales Acusatorios en América Latina. Ediciones Didot, Buenos Aires.
Guevara, A. 2015. El peritaje antropológico en la Corte Superior de Justicia de Loreto. En El Peritaje Antropológico. Entre la Reflexión y la Práctica, editado por A. Guevara, A. Verona y R. Vergara, pp. 167-204. Centro de investigación, capacitación y asesoría jurídica (CICAJ), Lima.

Le Bonniec, F. 2008. Crónica de un juicio antiterrorista contra los dirigentes mapuche. Imposición y uso del derecho entre los mapuche de Chile. En Luchas Indígenas, Trayectorias Poscoloniales: Américas y Pacífico, editado por A. Santamaría, B. Bosa y E. Wittersheim, pp. 107-138. Editorial Universidad del Rosario, Bogotá.

Leiva, R. 2013. Maremoto 1960, sacrificio humano y restablecimiento del equilibrio en el Wallmapu. Investigaciones Sociales 17 (30):35-45.

Mardones, M. 1955. Jurisprudencia. Sección cuarta. Jurisdicción criminal. Revista de Derecho y Jurisprudencia y Gazeta de los Tribunales, Tomo LII, 5-6:85-102.

Montecino, S. 2011. Mito, sacrificio y políticas de la diferencia: el terremoto del 60 en el lago Budi. Revista Anales 1:201-206.

Sánchez Botero, E. 2010. El Peritaje Antropológico. Justicia en Clave Cultural. Deutsche Gesellschaft für, Bogotá.

Sousa Santos, B.y J.L.Exeni2012.Justicia Indígena, Plurinacionalidad e Interculturalidad en Bolivia. Abya-Yala, Fundación Rosa Luxemburgo, La Paz.

Turner, V. 2008. La Selva de los Símbolos. Aspectos del Ritual Ndembu. Siglo XXI, Madrid.

Verona, A. 2015. ¿Pluma o espada? La desnaturalización del peritaje antropológico. Análisis de seis peritajes. En El Peritaje Antropológico. Entre la Reflexión y la Práctica, editado por A. Guevara, A. Verona y R. Vergara, pp. 205- 215. Centro de investigación, capacitación y asesoría jurídica (CICAJ), Lima.

Villegas, M. 2012. Entre la exculpación y la justificación. Apuntes de legislación comparada latinoamericana sobre pluralismo jurídico y derecho penal. Revista de Derecho (Valdivia) XXV (2):177-205. 
Notas

${ }^{1}$ Entre los nueve pueblos originarios existentes actualmente en Chile, el pueblo mapuche constituye el más numeroso y políticamente activo. Desde 1883 ha sido víctima de procesos de integración forzada al Estado y la sociedad chilena, perdiendo gran parte de su territorio ancestral autónomo, lengua y en menor medida cultura que, entre las nuevas generaciones, constituyen los principales motivos de reclamos y reivindicaciones.

2 Aun cuando la Declaración de Naciones Unidas de los Derechos de los Pueblos Indígenas (DNUDPI) data de 2007, y la defensa del caso es del 2013, la defensora a cargo solo alude al Convenio 169 de la OIT, ratificado por el Estado chileno en septiembre de 2008. Junto con estos instrumentos, el Estado chileno ha afirmado otras normas y estándares internacionales en materia de derechos humanos e indígenas que lo obligan jurídica, moral y materialmente a actuar con respeto frente a las diferencias socioculturales, lingüísticas, raciales, de género, religión, capacidades (físicas, psíquicas e intelectuales), orientación sexual y edad.

${ }^{3}$ Esta figura penal se encuentra prevista y sancionada en la ley 20.480 de 2010 y en el artículo 390 inciso segundo del Código Penal chileno, que la define como el homicidio cometido contra la mujer que es o ha sido cónyuge o conviviente del autor del crimen.

${ }^{4}$ Específicamente se analizó la solicitud de peritaje antropológico, dos informes antropológicos, la totalidad de los registros de audio con las declaraciones de los involucrados en el juicio y la sentencia del caso RIT 107-2013 por parte del tribunal.

${ }^{5}$ Se analizó la sentencia contra Juana Catrilaf, Valdivia, 7 de diciembre de 1953.

${ }^{6}$ Se analizó la sentencia contra Juan José Painecura Paineo y otros. Proceso $n^{\circ}$ 24.228. Homicidio. Nueva Imperial, 2 de octubre de 1962.

${ }^{7}$ Preocupación traducida en la ya citada ley 20.480 que establece el femicidio como delito, aumenta las penas y modifica la ley 20.066 de violencia intrafamiliar del año 2005.

${ }^{8}$ La norma se refiere a "el que por cualquier causa, independiente de su voluntad, se halla privado totalmente de razón".

9 "El que obra violentado por una fuerza irresistible o impulsado por un miedo insuperable".

${ }^{10}$ Respectivamente, el Ministerio Público y las hijas del matrimonio, además del Servicio Nacional de la Mujer (Sernam).

${ }^{11}$ En la sociedad mapuche contemporánea, los y las machi son considerados autoridades médicas, espirituales, morales y sociopolíticas. Como agentes médicos, son quienes manejan los conocimientos y métodos para enfrentar los desequilibrios físicos, mentales y espirituales de las personas para restablecer la salud orden. Para la defensa era necesario, entonces, contar con el punto de vista de los expertos del área, en este caso los machi, cuya visión vertebró la construcción argumental.

${ }^{12}$ Según Caniullan y Mellico (2017), los kalku son personas que, por envidia, pueden provocar desequilibrios en la tierra, la familia y las posesiones de terceros.

${ }^{13}$ Mapuche kutran y winka kutran, enfermedades mapuche y extranjeras. Dentro de las primeras, se refirió a las re kutran, kishu kutran, mapu kutran y weza kutran, respectivamente: enfermedades naturales, propias (de autoridades tradicionales), de las energías de la tierra y provocadas por terceros.

${ }^{14}$ Enfermedad natural, física u orgánica producida por cambios ambientales, meteorológicos o derivadas de desórdenes alimentarios (Caniullan y Mellico 2017; Citarella et al. 1995).

${ }^{15}$ Desequilibrio provocado por fuerzas de la naturaleza (Caniullan y Mellico 2017).
${ }^{16}$ Caniguan (2013) advierte sobre el carácter límite de la acción, adoptada después de agotar todas las instancias rituales posibles según la tradición: rogativas y sacrificios de aves y animales (ver pp. 75-76).

${ }^{17}$ Situación que se conoce en la jerga jurídica de los países latinoamericanos como "error de prohibición", es decir, "aquel que impide la comprensión de la antijuridicidad, esto es, la contrariedad de la conducta con el derecho, sin que se afecte el conocimiento de los elementos del tipo. [...] esta no comprensión de la antijuridicidad se traduce en la inexistencia de la conciencia de la ilicitud" (DPP 2012:162).

${ }^{18}$ En cuyo caso, los defensores pueden recurrir al "error de comprensión culturalmente condicionado", es decir, aquel que surge de la incomprensión de la antijuridicidad en virtud de la ausencia de endoculturación referida a las normas y valores de la sociedad dominante. "El error de comprensión culturalmente condicionado excluye la culpabilidad cuando el sujeto por su cultura o sus costumbres no comprenda la criminalidad de su conducta o no se le pueda exigir que adecue su conducta a esta comprensión" (DPP 2012:165). El modelo de defensa penal indígena de la DPP de Chile asocia directamente la referencia a este recurso de defensa con el uso de peritaje antropológico (DPP 2012:255).

${ }^{19}$ Tarea asumida en ambos casos por el médico y etnólogo Alejandro Lipschutz. De acuerdo con Montecino (2011), en el caso del Budi, Lipschutz contó además con la colaboración de la académica Grete Motsny.

${ }^{20}$ No existen antecedentes disponibles respecto del peritaje antropológico realizado en el caso del sacrificio humano, aunque podemos suponer que, al haber sido realizado por el mismo perito, su método de estudio pudo haber sido similar al desarrollado en el caso de Trafun.

${ }^{21}$ De acuerdo con Caniullan y Mellico (2017:46), corresponde a "la experiencia de persecución de un newen [fuerza espiritual] a una persona".

${ }^{22}$ A pesar de la importancia que tiene esta referencia en el caso, su definición y profundización fueron obviadas en la construcción argumental de la defensa, testigo y perito. Su mención no figura en la sentencia y solo pudo ser rastreada mediante la escucha atenta de los audios del juicio.

${ }^{23}$ Los peritos indigenistas agregan que "al matar a su propia abuela... la reo cumple con un requisito que, en el marco de la realidad mental de la comunidad primitiva en que vive, es de orden verdaderamente moral. Es un acto de auto-defensa y de defensa de la comunidad que la rodea" (Mardones 1955:89), del mismo modo que lo era la inquisición en el mundo europeo y americano del siglo XVII-XVIII.

${ }^{24}$ En ambos casos prevaleció, por parte de los jueces, un uso tácito y para entonces no elaborado de lo que en la dogmática penal latinoamericana se denomina "error de prohibición" y "error de comprensión culturalmente condicionado". Ver notas 17 y 18.

${ }^{25} \mathrm{La}$ autora se refiere al caso de una joven mujer que "se ponía violenta y atacaba a sus hermanos y hermanas, pero después no recordaba nada" (Bacigalupo 2001:51). Señala también que las personas manifiestan depresión, llanto sin motivo, tristeza, deseos de escapar de algo, pesadillas y comportamientos extraños o violentos hacia personas y pertenencias (ver p. 50).

${ }^{26}$ Este fenómeno ha sido advertido en distintos países latinoamericanos en los cuales la defensa apela a una suerte de inimputabilidad natural de los indígenas (Guevara 2015; Sánchez Botero 2010; Verona 2015). 